\title{
Strength and fluidity of cemented paste backfill at Qijiaojing Iron Mine, Northwest China
}

\author{
Mingqing Huang University of Science and Technology Beijing, China \\ Qian Gao University of Science and Technology Beijing, China
}

\begin{abstract}
Open stope mining with sequent backfilling was the major method adopted at Qijiaojing Iron Mine, and mix proportions of backfill materials were performed to produce the industrially required cemented paste backfill (CPB). The materials mainly comprise unclassified extra-fine tailings, waste rocks and Portland cements, and the experiments of the mix proportions followed the $L_{16}\left(4^{5}\right)$ orthogonal design. The results showed that contents of -20 and $-37 \mu m$ extra-fine grains within tailings accounted for 54 and $69 w t \%$, respectively. The range analysis of orthogonal experiments shows that mass concentration, tailing-waste ratio and wastecement ratio are the most to least sensitive factors to the slurry slump, 3-day and 7-day strengths. For 28-day strength, the sensitive variables are sequentially mass concentration, waste-cement ratio and tailing-waste ratio. Additionally, the optimal mix proportion for cement paste backfill is obtained with a mass concentration of $78 w t \%$, a tailing-waste ratio of 0.7 and a waste-cement ratio of 25. The slump and 28-day strength of the optimal CPB are $25.2 \mathrm{~cm}$ and $1.29 \mathrm{MPa}$, respectively.
\end{abstract}

\section{Introduction}

During the past few decades, cemented paste backfilling has been increasingly attractive for metal mines worldwide(Koohestani et al., 2016) as it is economical, safe and environmental friendly. It not only utilizes enormous waste rocks and tailings but also effectively fills the underground voids. Compared with backfill that uses traditional materials, the cemented paste backfill (CPB) features little separation, segregation and dehydration (Aldhafeeri and Fall, 2016) and is mainly used to prevent the collapse of roofs and pillars and to support a solid work platform in mined stopes. Therefore, its strength needs to be precisely designed to balance the safety effects and economic input. CPB is usually transported to underground voids using piston pumps, and due to its high concentration and great resistance, its fluidity is strictly required. Hence, strength and fluidity are key preconditions for the implementation of cemented paste backfilling.

Qijiaojing Iron Mine is located in Gobi desert in northwest China at an altitude of $2300 \mathrm{~m}$ and with an iron reserve of over 110 million tons. Ores are extracted using sublevel open stoping with subsequent backfilling. The combined effects of pillar and backfilling materials control the ground pressure, and therefore the strength of CPB only needs to support itself with over $0.5 \mathrm{MPa}$ required. In this work, attention has been paid to optimize the mix proportions of backfilling raw materials to produce the CPB with satisfactory fluidity and strength. Firstly, a batch of orthogonal experiments on the mix proportions of CPB are carried out using unclassified raw ultra-fine tailings, waste rocks and cements. Secondly, range analysis is conducted to investigate the sensitivities of independent variables to dependent variables. In this case, the independent variables include slurry mass concentration, tailing-waste ratio and waste-cement ratio, and the dependent variables include paste slump and strength. Furthermore, the optimal mix proportion of CPB with targeted properties is proposed according to the regression analysis. The work shows a feasible way to produce the industrial standard CPB for Qijiaojing Iron Mine. 


\section{Methods and materials}

\subsection{Materials}

The unclassified tailings were directly sampled from the discharge pipes of the processing plant. The laser particle analyzer showed that the gradations below 20,37 and $74 \mu \mathrm{m}$ were 54,69 and $87 \%$, respectively. The chemical analysis revealed that the tailings contained $50.63 \% \mathrm{SiO}_{2}, 25.54 \% \mathrm{Fe}_{2} \mathrm{O}_{3}, 9.39 \% \mathrm{CaO}, 5.39 \% \mathrm{MgO}$, $2.72 \% \mathrm{Al}_{2} \mathrm{O}_{3}$ and $1.92 \% \mathrm{SO}_{3}$; despite a relatively wide range of distribution of the tailings grain size, a smooth and continuous distribution was also observed (Figure 1).

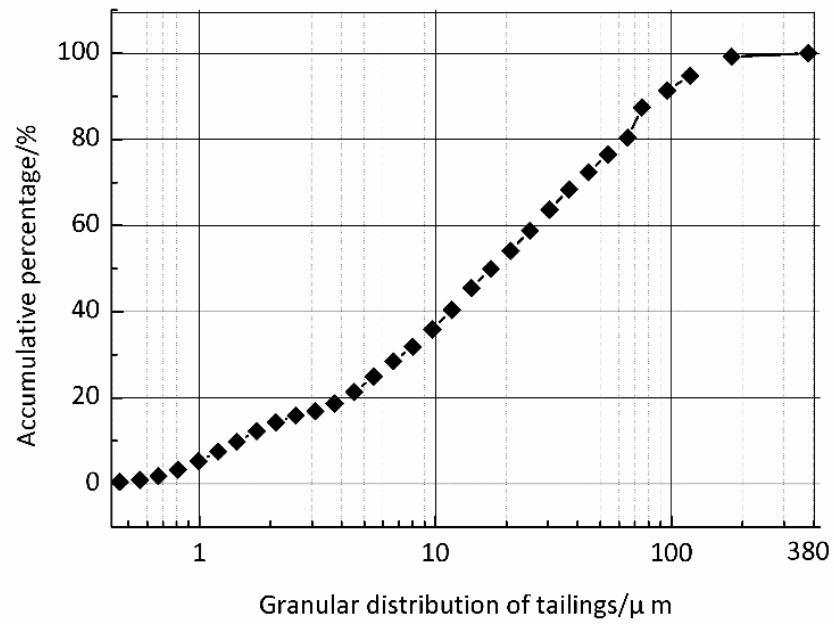

Figure 1 The granular distribution of the tailings at Qijiaojing Iron Mine

Waste rocks mined out from underground stopes were milled to $-5 \mathrm{~mm}$ before being delivered to the processing plant. The X-ray fluorescence test showed that the composition of rocks were similar to that of tailings. The 32.5R Portland cement chosen as the binder to produce the CPB was supplied form a local cement plant and has a specific surface area of $380 \mathrm{~m}^{2} / \mathrm{kg}$ and specific gravity of $3050 \mathrm{~kg} / \mathrm{m}^{3}$.

\subsection{Experimental scheme}

Following the orthogonal approach (Suttaphakdee et al., 2016), a total of 16 mix proportions of CPB were designed according to the $\mathrm{L}_{16}\left(4^{5}\right)$ orthogonal array (Table 1 ). Slurry mass concentration, tailing-waste (waste means tailings and rocks) ratio and waste-cement ratio were designed as the independent variables, whereas slurry slump, uniaxial compressive strength (UCS) on day 3 (R3), 7 (R7) and 28 (R28) were taken as dependent variables. Slurry mass concentrations were in the range of $77 \sim 80 \mathrm{wt} \%$, the tailing-waste ratio of $0.7 \sim 0.9$, and the waste-cement ratio of $15 \sim 30$.

Table 1 Orthogonal design of CPB mix proportions

\begin{tabular}{cccccccc}
\hline Mixture & \multicolumn{2}{c}{ Density tailing-waste waste-cement } & \multicolumn{3}{c}{ Density tailing-waste waste-cement } \\
\hline & (wt\%) & ratio & ratio & Mixture & (wt\%) & ratio & ratio \\
\hline 1 & 77 & 0.9 & 30 & 9 & 79 & 0.9 & 20 \\
2 & 77 & 0.85 & 25 & 10 & 79 & 0.85 & 15 \\
3 & 77 & 0.8 & 20 & 11 & 79 & 0.8 & 30 \\
4 & 77 & 0.7 & 15 & 12 & 79 & 0.7 & 25 \\
5 & 78 & 0.9 & 25 & 13 & 80 & 0.9 & 15 \\
6 & 78 & 0.85 & 30 & 14 & 80 & 0.85 & 20 \\
7 & 78 & 0.8 & 15 & 15 & 80 & 0.8 & 25 \\
8 & 78 & 0.7 & 20 & 16 & 80 & 0.7 & 30 \\
\hline
\end{tabular}


All mixtures were prepared according to the designed mix proportions of tailings, rocks, cement and water. After testing the slumps, each mixture was divided into nine duplications, each placed into a cylinder steel mould, $80 \mathrm{~mm}$ in diameter and $200 \mathrm{~mm}$ in height, and cured for 24 hours at ambient temperatures. All mixtures were then moved to the curing room at $30^{\circ} \mathrm{C}$ and with a relative humidity of $95 \%$. At 3-day, 7-day and 28-day intervals, three samples for each concreted mixture were cut for UCS tests into standard test specimen $80 \mathrm{~mm}$ in diameter and $160 \mathrm{~mm}$ in height.

The slurry slump testing followed the national standard for test method of performance on ordinary fresh concrete (GB/T 50080-2002) (Ministry of Construction, 2003a). The UCS tests were carried out according to the national standard for test method of mechanical properties on ordinary concrete (GB/T 50081-2002) (Ministry of Construction, 2003b).

\subsection{Analysis methods}

Range analysis was introduced to understand the impacts of the key factors on the slumps and strengths of CPT. It provides a reliable way to select the best runs for each factor and the best mix proportions at initial parameters. The range $R$ refers to the maximum difference value in each experimental run for each influential factor, given as follows:

$$
R_{j}=\max _{r}-\min _{r}
$$

where $j$ is the sequence number of key factors, $j=1,2, \ldots N ; r$ is the sequence number of the experimental run for each factor, $r=1,2, \ldots \mathrm{M} ; K_{r}$ is the average value of all runs of $r$ for factor $j$.

The data processing system (DPS) software was introduced for the regression analysis of independent variables and dependent variables. A satisfying fitting effect of the experimental results usually requires the regression parameters to meet certain limits. For instance, the correlation coefficient $R$ of the regression equation has to be higher than 0.9 and significant level $p$ lower than 0.05 .

\section{$3 \quad$ Results and discussion}

\subsection{Range analysis of slump and strength}

The range analysis of slurry slumps (Table 2 ) shows a wide diversity of ranges for the three independent variables. Unsurprisingly, mass concentration (referred to as $a$ in Table 2), whose range $R$ is 15.4, is the most sensitive factor to influence the slurry slump. The second and the third sensitive factors are respectively tailing-waste ratio (referred to as $b, R=8.0$ ) and waste-cement ratio (referred to as $c, R=3.6$ ). Therefore, the best run for the above three influential factors is $77 \mathrm{wt} \%$ mass concentration, tailing-waste ratio of 0.7 and waste-cement ratio of 25 .

Table 2 Range analysis of slurry slump and CPB strength

\begin{tabular}{ccccc}
\hline Range Analysis & Slump $(\mathrm{cm})$ & $\mathbf{R 3}(\mathrm{MPa})$ & $\mathbf{R 7}(\mathrm{MPa})$ & $\mathbf{R 2 8}(\mathrm{MPa})$ \\
\hline range A & 15.4 & 0.12 & 0.35 & 3.83 \\
range B & 8.0 & 0.09 & 0.22 & 0.19 \\
range C & 3.6 & 0.04 & 0.19 & 0.76 \\
significance & $\mathrm{A}>\mathrm{B}>\mathrm{C}$ & $\mathrm{A}>\mathrm{B}>\mathrm{C}$ & $\mathrm{A}>\mathrm{B}>\mathrm{C}$ & $\mathrm{A}>\mathrm{C}>\mathrm{B}$ \\
best run & $\mathrm{A} 1, \mathrm{~B} 4, \mathrm{C} 2$ & $\mathrm{~A} 4, \mathrm{~B} 1, \mathrm{C} 4$ & $\mathrm{~A} 4, \mathrm{~B} 1, \mathrm{C} 4$ & $\mathrm{~A} 4, \mathrm{~B} 3, \mathrm{C} 4$ \\
best mixture & $\mathrm{A} 1 \mathrm{~B} 4 \mathrm{C2}$ & $\mathrm{A} 4 \mathrm{~B} 1 \mathrm{C4}$ & $\mathrm{A} 4 \mathrm{~B} 1 \mathrm{C} 4$ & $\mathrm{~A} 4 \mathrm{~B} 3 \mathrm{C} 4$ \\
\hline
\end{tabular}

Following the same analytical approach, the results of the range analysis indicate that mass concentrations dominant the sensitivity to R3, R7 and R28. However, although tailing-waste ratio is the second sensitive factor to R3 and R7, it turns out to be the third one to R28. From Table 2, the best optimum mix proportion for R3 and R7 can be derived as A4B1C4 (80wt\%, tailing-waste ratio of 0.9 and waste-cement ratio of 15), 
while the optimal combination is A4B3C4 ( $80 \mathrm{wt} \%$, tailing-waste ratio of 0.8 and waste-cement ratio of 15$)$ for R28.

Furthermore, the regression analysis quantitatively demonstrates the relationships between independent and dependent variables. The slurry slump $y_{1}$, the 3-day uniaxial compressive strength (R3) $y_{2}, \mathrm{R} 7 y_{3}$ and R28 $y_{4}$ can be predicted using the following equations (Equations 2 to 5 ). All regression equations show high correlation coefficients, indicating satisfying fitting effects of experimental results.

$$
\begin{aligned}
y_{1}= & 5810.2-162.4 x_{1}+1601.8 x_{2}+12.5 x_{3}+1.14 x_{1}^{2}+19.7 x_{2}^{2}-0.03 x_{3}^{2}-21.7 x_{1} x_{2} \\
& \quad-0.2 x_{1} x_{3}+0.8 x_{2} x_{3} \\
y_{2}= & 5206-1.23 x_{1}-13.8 x_{2}+0.028 x_{3}+0.007 x_{1}^{2}+0.19 x_{1} x_{2}-0.04 x_{2} x_{3} \\
y_{3}= & 477.7-12.6 x_{1}+9.4 x_{2}+0.85 x_{3}+0.008 x_{1}^{2}-4.91 x_{2}^{2}-0.01 x_{1} x_{3}-0.05 x_{2} x_{3} \\
y_{4}= & 3215.3-83.9 x_{1}+30.9 x_{2}+1.8 x_{3}+0.55 x_{1}^{2}-21.1 x_{2}^{2}-0.02 x_{1} x_{3}+0.04 x_{2} x_{3}
\end{aligned}
$$

where $x_{1}$ is the mass concentration of CPB; $x_{2}$ is the tailing-waste ratio; $x_{3}$ is the waste-cement ratio; when the correlation coefficient $R=0.99$, the significant level $p=0.0001<0.05$ in Equation 2; when the correlation coefficient $R=0.91$, the significant level $p=0.0044<0.05$ in Equation 3; when the correlation coefficient $R=0.98$, the significant level $p=0.0006<0.05$ in Equation 4; when the correlation coefficient $R=0.98$, the significant level $p=0.0001<0.05$ in Equation 5.

\subsection{Optimization of mix proportions}

An ideal mix proportion of CPB must simultaneously meet the slump and strength standards. To obtain a fluent fluidity during pumping, the slurry slump is always restricted within $23 \sim 26 \mathrm{~cm}$. The use of open stope mining with sequent backfilling and the relatively long transfer period from the lower stage to the upper stage (usually several months) makes the 3-day and 7-day strengths less favorable choices. Hence, 28-day strength is designed to be a primary factor, and it only has to be higher than $0.5 \mathrm{MPa}$.

As the range analysis indicated, mass concentration is the most significant independent variable in all cases. When the tailing-waste ratio is 0.7 and the waste-cement ratio is 25 , slump slurry decreases as the mass concentration increases, while R28 shows a rising trend during the same period (Figure 2). Considering the favorable slump ranges, $78 \mathrm{wt} \%$ mass concentration is an optimal value.

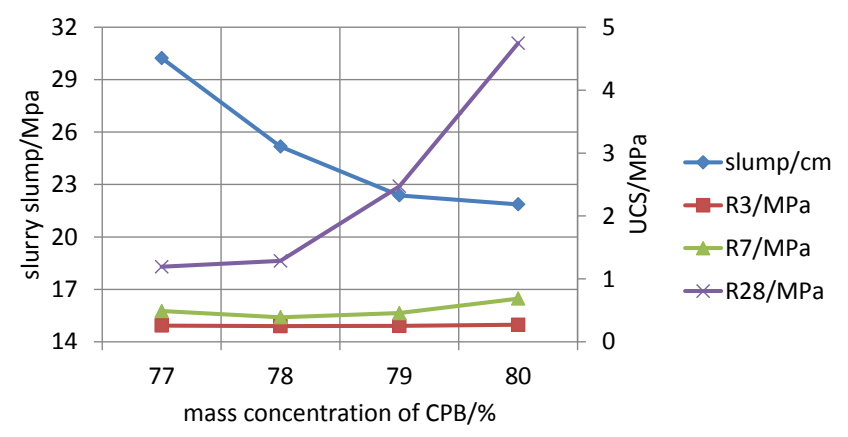

Figure 2 The variations of slurry slump and CPB strengths as mass concentration increases

When the mass concentration is $78 \mathrm{wt} \%$ and the tailing-waste ratio is 0.7 , all slurry slumps meet the industrial standards within the experimental ranges of waste-cement ratios (Figure 3). However, with the increase of waste-cement ratio, R28 linearly decreases to only $1.09 \mathrm{MPa}$ at the waste-cement ratio of 30 . To reduce the consumption of expensive cements, the waste-cement ratio of 25 becomes a balanced alternative between the slurry slump and R28. 


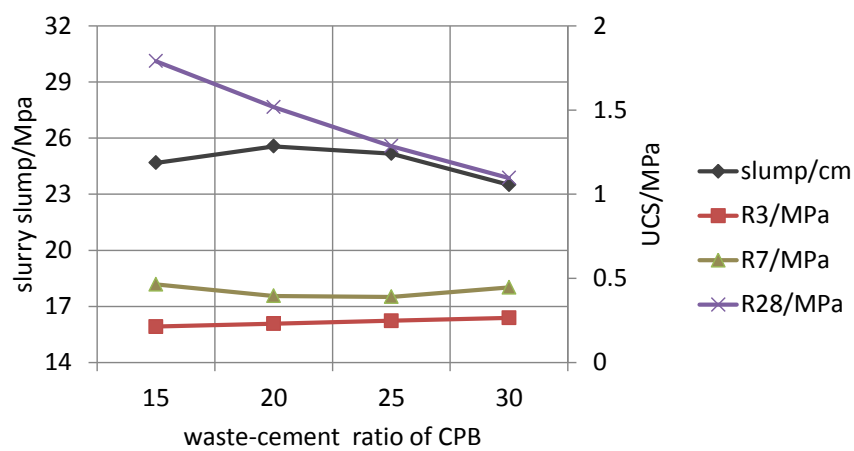

Figure 3 The variations of slurry slump and CPB strengths as waste-cement ratio increases

When mass concentration is $78 \mathrm{wt} \%$ and the waste-cement ratio is 25 , an increase in the tailing-waste ratio results in a dramatic decrease in the slump slurry (Figure 4). Under this trend, CPB becomes hardly pumpable when the tailing-waste ratio is greater than 0.7. Additionally, R28 shows a slight rise when the tailing-waste ratio is below 0.8 but sees a rapid decrease afterwards. Therefore, the optimal tailing-waste ratio is 0.7 .

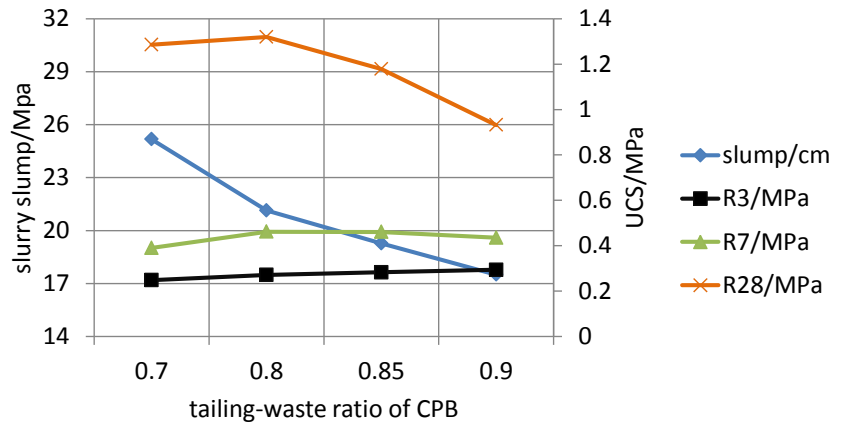

Figure 4 The variations of slurry slump and CPB strengths as tailing-waste ratio increases

Hence, the optimal mix proportion of $\mathrm{CPB}$ is $78 \mathrm{wt} \%$ mass concentration, tailing-waste ratio of 0.7 and wastecement ratio of 25 . With this precondition, the slurry slump is predicted to be $25.2 \mathrm{~cm}$, and 28-day uniaxial compressive strength achieves $1.29 \mathrm{MPa}$, with which the open stope mining with sequent backfilling can be employed safely and relatively economically.

\section{Conclusions}

Tailings at Qijiaojing Iron Mine have a relatively wide range as well as a smooth and continuous distribution, and are classified as ultra-fine tailings with $54 \mathrm{wt} \%-20 \mu \mathrm{m}$ grains. For open stope mining with sequent backfilling method, the CPB that meet the industrial standards can be produced with ultra-fine tailings, $-5 \mathrm{~mm}$ waste rocks and Portland 32.5R cement.

The range analysis of orthogonal experiments shows that the mass concentration, tailing-waste ratio and waste-cement ratio are the most to the least sensitive factors to slurry slump, 3-day and 7-day strength. For the 28-day strength, the sensitive variables are sequentially mass concentration, waste-cement ratio and tailing-waste ratio.

The optimal mix proportion for cement paste backfill with extra-fine unclassified tailings is obtained with a mass concentration of $78 \mathrm{wt} \%$, a tailing-waste ratio of 0.7 and a waste-cement ratio of 25 . The slump and 28day strength of CPB are $25.2 \mathrm{~cm}$ and $1.29 \mathrm{MPa}$, respectively. 


\section{Acknowledgements}

The authors would like to acknowledge the financial support provided by China Postdoctoral Science Foundation (2017M610773), the Beijing Municipal Science Plan Program (Z161100001216002) and the National Natural Science Foundation of China (51574013).

\section{References}

Aldhafeeri, Z., and Fall M. 2016, 'Time and damage induced changes in the chemical reactivity of cemented paste backfill', Journal of Environmental Chemical Engineering, vol. 4, pp. 4038-4049.

Koohestani, B., Koubaa, A., Belem, T., Bruno Bussièrea, B., and Bouzahzaha H. 2016, 'Experimental investigation of mechanical and microstructural properties of cemented paste backfill containing maple-wood filler', Construction and Building Materials, vol. 121, pp. 222-228.

Ministry of Construction of the People's Republic of China 2003, 'Standard for test method of performance on ordinary fresh concrete (GB50080-2002) ', China Building Industry Press Beijing, Beijing, pp. 1-40.

Ministry of Construction of the People's Republic of China, 'Standard for test method of mechanical properties on ordinary concrete (GB50081-2002) ', China Building Industry Press Beijing, Beijing, pp. 1-66.

Suttaphakdee, P., Dulsang, N., Lorwanishpaisarn, N., Kasemsiri, P., and Chindaprasirt, P. 2016, 'Optimizing mix proportion and properties of lightweight concrete incorporated phase change material paraffin/recycled concrete block composite', Construction and Building Materials, vol. 127, pp. 475-483. 